\title{
Erratum to: Drug Abuse in China: Past, Present and Future
}

\author{
Lin Lu $\cdot$ Yuxia Fang $\cdot$ Xi Wang
}

Published online: 15 November 2009

(C) Springer Science+Business Media, LLC 2009

Erratum to: Cell Mol Neurobiol (2008) 28:479-490

DOI 10.1007/s10571-007-9225-2

The legend of Fig. 2 on page 483 should be "Proportion of reported drug addicts in different areas of China (from Annual Report on Drug Abuse in China, 2006)". The sentence in line 1 of page 482 "In the past decade, drug abuse has also become evident in rural areas, especially in the northwest and central regions of the country (Fig. 2)" should be "In 2006, drug abuse has become evident in most areas of China, especially in the southwest and central regions of the country (Fig. 2)."

The online version of the original article can be found under doi:10.1007/s10571-007-9225-2.

L. Lu $(\bowtie) \cdot X$. Wang

National Institute on Drug Dependence, Peking University,

Beijing 100083, China

e-mail: linlu@bjmu.edu.cn

Y. Fang

Clinical Pharmacology and Therapeutics Branch, Intramural Research Program, National Institute on Drug Abuse, National Institutes of Health, Baltimore, MD 21224, USA 